\title{
ARTICLE OPEN \\ Patient-reported outcomes in primary care patients with COPD: psychometric properties and usefulness of the Clinical COPD Questionnaire (CCQ). A cross-sectional study
}

\author{
Antoinette M Pommer ${ }^{1}$, François Pouwer ${ }^{1}$, Johan Denollet ${ }^{1}$, Jan-Willem Meijer ${ }^{2}$ and Victor J Pop ${ }^{1}$
}

BACKGROUND: Chronic obstructive pulmonary disease (COPD) is a common disease with considerable consequences for patients' daily lives. The Clinical COPD Questionnaire (CCQ) was designed to measure these consequences in daily practice. Although the CCQ is widely used, its original structure has never been tested.

AIMS: This study examines the psychometric properties of the CCQ with regard to its latent structure in a sample of primary care patients with COPD.

METHODS: Two cross-sectional studies were conducted; in study $1(N=243)$ exploratory analyses, including exploratory factor analysis (EFA) and Mokken scale analysis, were performed to explore the latent structure of the CCQ. In study $2(N=244)$, confirmatory factor analysis (CFA) was conducted to evaluate the model fit of the structure found in study 1.

RESULTS: Both EFA and Mokken scale analysis revealed a structure of two dimensions ('general impact' $a=0.91$ and 'cough' $a=0.84$ ). This structure, however, was not confirmed in study 2 , nor was the original structure. However, subsequently removing items that violated the assumption of a normal response distribution did result in an excellent model fit with two dimensions measuring 'dyspnoea' and 'cough' (CFA: comparative fit index (CFI) 0.98; normed fit index (NFI) 0.97; root mean squared error of approximation (RMSEA) 0.08 (0.04)).

CONCLUSIONS: In primary care, factor analyses on the CCQ revealed a two-component structure measuring 'general impact', and 'cough'. A shortened and more specific version of the CCQ could be regarded as a useful instrument to screen for exacerbations by measuring dyspnoea, coughing and producing phlegm.

npj Primary Care Respiratory Medicine (2014) 24, 14027; doi:10.1038/npjpcrm.2014.27; published online 17 July 2014

\section{INTRODUCTION}

Chronic obstructive pulmonary disease (COPD) places a considerable burden on patients' daily lives ${ }^{1}$ and is the fourth leading cause of death worldwide. ${ }^{2}$ Although the forced expiratory volume in $1 \mathrm{~s}\left(\mathrm{FEV}_{1}\right)$ has long been the gold standard to determine COPD severity, it is now well known that COPD is a multi-component disease and that ' $\mathrm{FEV}_{1}$ is an unreliable marker of the severity of breathlessness, exercise limitation, and health status impairment'. ${ }^{1}$ Therefore, in their guidelines of 2011, the Global Initiative for Chronic Obstructive Lung Disease (GOLD) suggests a combined COPD assessment in which the patients' spirometric classification should be combined with a more patient-centred assessment of symptoms. ${ }^{1}$

In 2003, Van der Molen et al. ${ }^{3}$ developed the Clinical COPD Questionnaire (CCQ) with the intention to incorporate both clinicians' and patients' treatment goals by assessing symptoms and functional state. The CCQ is a short, 10-item scale that measures 'clinical control', which was defined as 'the full range of clinical impairment that patients with COPD may experience as a result of their disease'. ${ }^{4}$ When developing a new instrument that will serve as a measure of patient-reported outcomes, it is strongly recommended to incorporate the patient's opinion. ${ }^{5}$ Therefore, 34 patients diagnosed with COPD were involved in the initial development of the CCQ through focus group discussions. ${ }^{3}$
However, the constructs and final content of the current CCQ were determined by clinicians and 'experts' in the field of COPD. These clinicians and experts received 16 potential items that derived from the focus group discussions, and were invited to rank them in the order of importance for the assessment of clinical COPD control; 10 items remained and were divided into three subscales: 'symptoms' 4 items, 'functional state' 4 items, and 'mental state' 2 items. Subsequently, the reliability and validity of the CCQ and its subscales were determined in a cross-sectional study involving 119 (mainly primary care) patients who were either 'healthy' ex-smokers, at risk of COPD or diagnosed with COPD (GOLD I-III).

Because the CCQ was among the first short and user friendly, disease-specific questionnaires, it has been translated in over 20 languages and become a widely used instrument in both clinical practice and clinical trials. Previous research has extensively studied the concurrent validity of the CCQ. However, its original latent structure of three dimensions has never been tested in replication studies. In addition, although studies claim that both the CCQ and its subscales are valid and reliable, ${ }^{3,6-11}$ the methodological approach of these studies has several limitations (e.g., $40 \%$ of these studies had a sample size $<100$ or included a rather heterogeneous COPD population). Moreover, when compared with other COPD-specific health status instruments, the CCQ often appears less reliable in measuring constructs like quality of life, ${ }^{12}$ functional status ${ }^{13}$ and breathlessness. ${ }^{14}$

${ }^{1}$ Department of Medical and Clinical Psychology, Centre of Research on Psychology in Somatic diseases (CoRPS), TSB, Tilburg University, Tilburg, The Netherlands and ${ }^{2}$ Revant, Pulmonary Rehabilitation Centre 'Schoondonck', Breda, The Netherlands.

Correspondence: VJ Pop, (V.J.M.Pop@tilburguniversity.edu)

Received 24 October 2013; revised 18 March 2014; accepted 25 March 2014 
Therefore, the aim of the present study was to examine the latent structure of the CCQ to provide better knowledge of its underlying dimensions and to further enhance the potential usefulness of this patient-reported outcome measure in clinical practice.

\section{MATERIALS AND METHODS}

\section{Setting}

This study was conducted in collaboration with PoZoB, a large primary care organisation in the south of the Netherlands. PoZoB supports $\sim 250$ general practitioners in organising their care for patients with a chronic disease through disease management programmes targeted at specific conditions such as diabetes, asthma and COPD. ${ }^{15}$ In 2008, PoZoB started a disease management programme for patients with asthma and mild to moderate COPD (GOLD I and GOLD II), the 'ASCOZOB' programme. ${ }^{16}$ All data in the present study were collected within this setting in patients diagnosed according to the GOLD guidelines.

\section{Participants and procedure}

During a 12-month period (2008-2009) all COPD patients within the ASCOZOB programme were invited to complete a set of questionnaires, including the CCQ, as part of a baseline assessment; questionnaires were sent by postal mail. Four hundred and two patients (20\%) completed and returned the CCQ. The data of this first sample were combined with the data of another sample of primary care patients with COPD from the same population. Data collection for this second sample started in 2011 and was part of a randomised controlled trial testing a disease management approach for co-morbid depression and anxiety in patients with COPD participating in the ASCOZOB programme. In accordance with the first sample, data came from a baseline assessment; an extensive description of the trial has been published elsewhere. ${ }^{17}$ Eighty-five patients (34\%) completed and returned the questionnaire resulting in an overall study sample of 487 primary care patients with COPD; missing values were replaced using expectation maximization imputation (missings per item varied from $0 \%$ (item 1 ) to $2 \%$ (item 7 )). Subsequently, this overall study sample was randomly divided into two separate subsamples for studies 1 and 2. The data of study 1 were used to explore the latent structure of the CCQ; the data of study 2 were used to confirm the scale structure found in study $1 .{ }^{18}$ Patient characteristics of studies 1 and 2 are presented in Table 1; all patients were diagnosed with COPD GOLD I or GOLD II.

Measurements and statistical methods

All patients completed a questionnaire including questions regarding demographics (sex, age, marital status, education level and smoking status) and the CCQ. Statistical analyses were performed using the
Statistical Package for Social Sciences (SPSS version 18.0, IBM, Chicago, IL, USA). Confirmatory factor analysis (CFA) was done using AMOS (version 18, IBM, Chicago, IL, USA).

Descriptive analyses. To test for differences between the two study samples, chi-square analyses were used for all categorical data (sex, marital status, education and smoking), continuous data (age) were analysed with an independent samples $t$-test.

Study 1. Exploratory analyses were conducted to discover the latent structure of the CCQ. First, skewness, kurtosis and response distributions were reviewed to explore the relevance of each item to the present patient population (Table 2). Subsequently, although factor analyses are relatively robust against violations of normality, ${ }^{19}$ both exploratory factor analysis (EFA) using principal axis factoring and oblimin rotation (Table 3) and Mokken scale analysis were performed to explore the structure of the CCQ. Mokken scale analysis is the non-parametric equivalent of EFA, based on the principles from item response theory, ${ }^{20}$ and is less sensitive to violations of normality. In EFA, Cattell's scree test and eigenvalues $(>1)^{21}$ were explored to determine the number of eligible factors; in the Mokken scale analysis the lower bound of the $\mathrm{H}$-coefficient was set to 0.4 (comparable to a factor loading of 0.4 ) to determine the latent structure. Finally, internal consistency was determined by calculating Cronbach's alphas.

Study 2. The structure found in study 1 was evaluated with CFA. Adequate fit can be assumed with comparative fit index $(\mathrm{CFI}) \geqslant 0.80$, in combination with normed fit index (NFI) $\geqslant 0.80$ and (the lower limit of) root mean squared error of approximation (RMSEA) $\leqslant 0.05$ for good and (lower limit) RMSEA $\leqslant 0.08$ for adequate fit. ${ }^{22-24}$

\section{Ethical principles}

This study was conducted in accordance with the principles described in the Declaration of Helsinki and in accordance with 'The Medical Research Involving Human Subjects Act' (Wet Maatschappelijke Ondersteuning) and approved by the medical ethics committee of the Elizabeth Hospital Tilburg, the Netherlands, NL33363.008.10.

\section{RESULTS}

The study samples of studies 1 and 2 were similar on all baseline characteristics as displayed in Table 1.

Table 1. Characteristics of patients with COPD in both study $1(N=243)$ and study $2(N=244)$

\begin{tabular}{|c|c|c|c|c|c|c|c|c|c|c|c|}
\hline Characteristics & \multicolumn{5}{|c|}{ Study 1: exploratory factor analysis } & \multicolumn{6}{|c|}{ Study 2: confirmatory factor analysis } \\
\hline \multicolumn{12}{|l|}{ Demographics } \\
\hline Sex & & & & & & & & & & & 0.26 \\
\hline Male & 147 & 62 & & & & 162 & 66 & & & & \\
\hline Female & 92 & 38 & & & & 82 & 34 & & & & \\
\hline Age & & & 67 & 10.7 & $35-88$ & & & 67 & 9.8 & $33-87$ & 0.95 \\
\hline Widowed & 27 & 11 & & & & 28 & 12 & & & & \\
\hline Single & 29 & 12 & & & & 32 & 13 & & & & \\
\hline Education level & & & & & & & & & & & 0.71 \\
\hline Low & 152 & 63 & & & & 150 & 62 & & & & \\
\hline Middle & 60 & 25 & & & & 66 & 28 & & & & \\
\hline High & 27 & 11 & & & & 25 & 10 & & & & \\
\hline
\end{tabular}


Table 2. Study 1: skewness, kurtosis and response distribution in $\%$ of all individual items

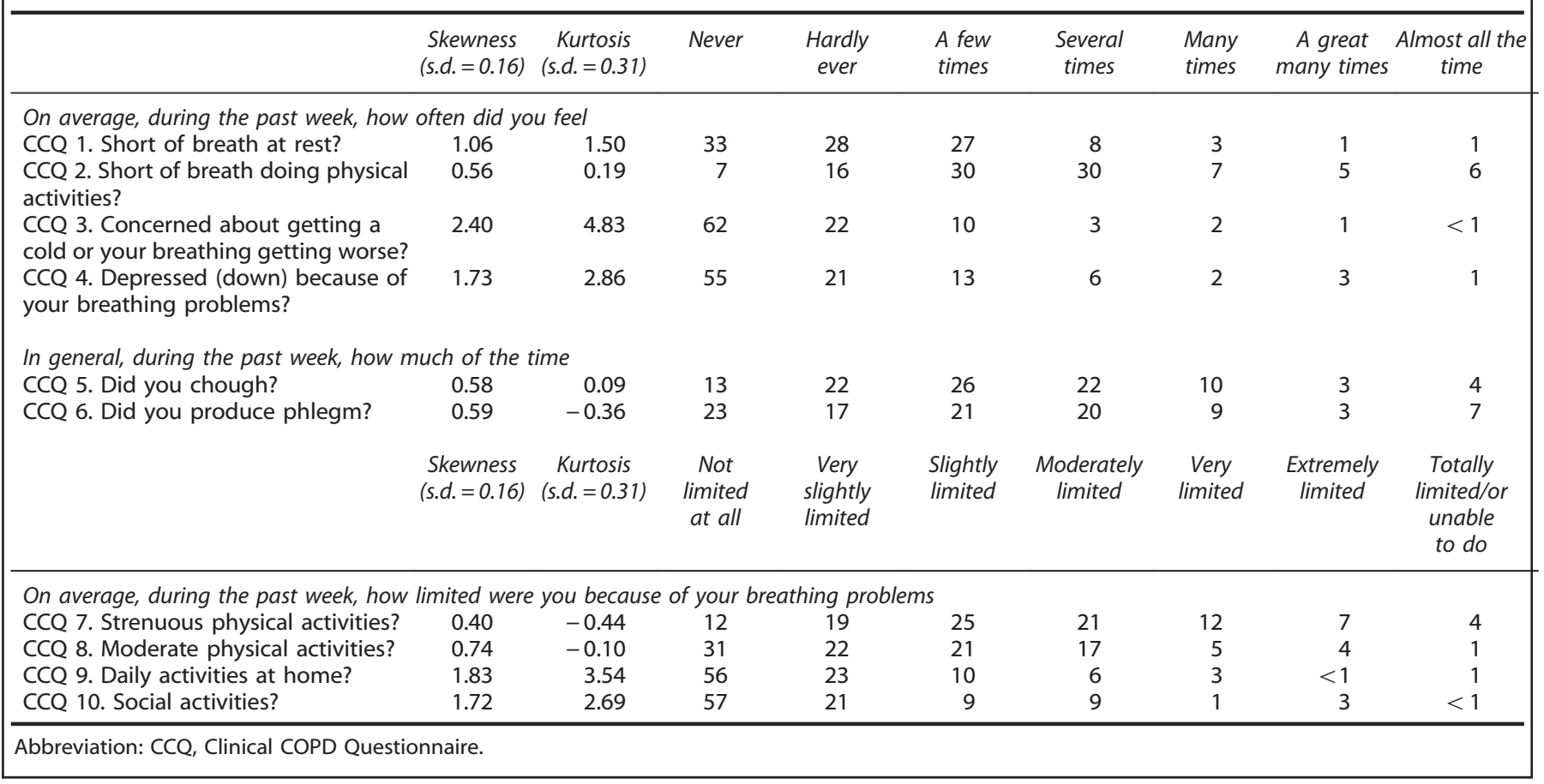

Table 3. Study 1: two-component structure from EFA using principal axis factoring with oblimin rotation; the structure matrix

\begin{tabular}{lcc}
\hline & Impact & Coughing \\
\hline Eigen values & 5.3 & 1.4 \\
Percentage of variance & 53.0 & 14.0 \\
& & \\
Factor loadings & 0.69 & 0.41 \\
CCQ 1. Short of breath & 0.70 & 0.47 \\
CCQ 2. Short of breath doing physical activities & \\
CCQ 3. Concerned about getting a cold or your & 0.70 & \\
breathing getting worse & & \\
CCQ 4. Depressed (down) because of your & 0.75 & \\
breathing problems & & 0.84 \\
CCQ 5. Did you cough? & 0.42 & 0.84 \\
CCQ 6. Did you produce phlegm? & 0.75 & 0.49 \\
CCQ 7. Limited in strenuous activities & 0.84 & 0.42 \\
CCQ 8. Limited in moderate physical activities & 0.75 & \\
CCQ 9. Limited in daily activities at home & 0.76 & \\
CCQ 10. Limited in social activities & & \\
\hline All factor loadings > 0.40 are displayed. & & \\
Abbreviations: CCQ, Clinical COPD Questionnaire; EFA, exploratory factor \\
analysis.
\end{tabular}

Initial analyses in study 1

Skewness and kurtosis of each individual item are displayed in Table 2. 'Floor effects' were found in four items as over $79 \%$ of patients indicated that the content of these items was not applicable to them: item 3, 'On average during the past week, how often did you feel concerned about getting a cold or your breathing getting worse?'; item 4, 'On average during the past week, how often did you feel depressed (down) because of your breathing problems?'; item 9, 'On average, during the past week, how limited were you in daily activities at home because of your breathing problems?'; item 10, 'On average, during the past week,

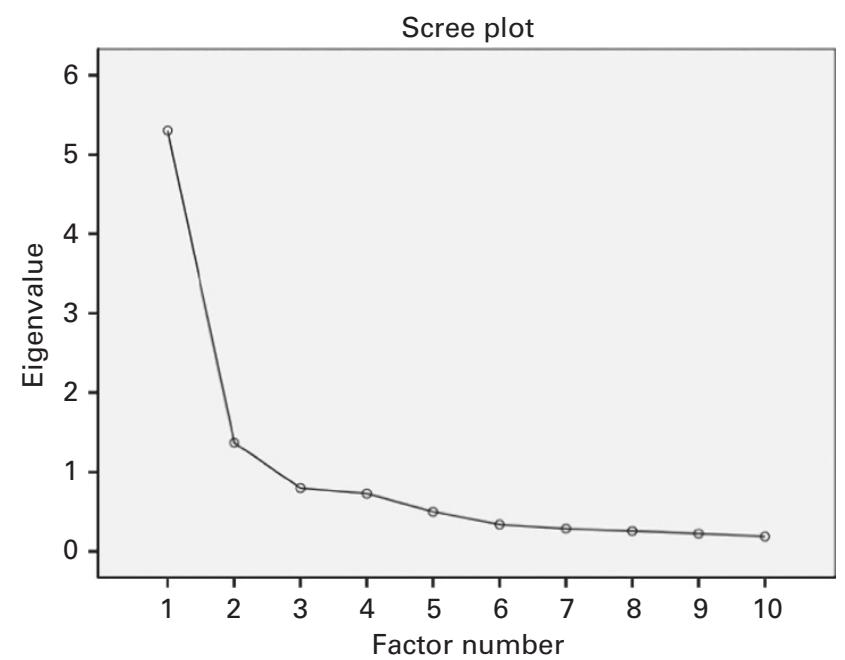

Figure 1. The scree plot from the exploratory factor analysis in study 1.

how limited were you in social activities because of your breathing problems?'

All assumptions to perform EFA were met, the Kaiser-MeyerOklin value was $>0.60(0.86)$ and Bartlett's test of sphericity was significant $(P<0.01)$. The scree test (Figure 1$)$ revealed a clear pattern of two dimensions that together explained $67 \%$ of all variance ('general impact' 53\% and 'cough' 14\%). In addition, all corresponding factor loadings were $>0.65$ (Table 3 ). With regard to the Mokken scale analysis, a lower bound of $0.4-0.5$ (comparable with factor loadings $>0.4$ ) resulted in the same two dimensions with sufficient differential quality $(\mathrm{H})$; the differential quality of 'general impact' varied between $\mathrm{H} 0.60$ (lower bound 0.4 ) and $\mathrm{H} 0.66$ (lower bound 0.5), with $\mathrm{H} 1.00$ suggesting perfect differential quality. The differential quality of 
Table 4. Study 2: skewness, kurtosis and response distribution in \% of all individual items

\begin{tabular}{|c|c|c|c|c|c|c|c|c|c|}
\hline & $\begin{array}{l}\text { Skewness } \\
\text { (s.d. }=0.16)\end{array}$ & $\begin{array}{l}\text { Kurtosis } \\
\text { (s.d. }=0.31)\end{array}$ & Never & $\begin{array}{l}\text { Hardly } \\
\text { ever }\end{array}$ & $\begin{array}{l}\text { A few } \\
\text { times }\end{array}$ & $\begin{array}{l}\text { Several } \\
\text { times }\end{array}$ & $\begin{array}{l}\text { Many } \\
\text { times }\end{array}$ & $\begin{array}{l}\text { A great } \\
\text { many times }\end{array}$ & $\begin{array}{l}\text { Almost all } \\
\text { the time }\end{array}$ \\
\hline \multicolumn{10}{|c|}{ On average, during the past week, how often did you feel } \\
\hline $\begin{array}{l}\text { CCQ } 2 \text {. Short of breath doing physical } \\
\text { activities? }\end{array}$ & 0.54 & -0.15 & 12 & 13 & 35 & 18 & 9 & 6 & 6 \\
\hline $\begin{array}{l}\text { CCQ 3. Concerned about getting a } \\
\text { cold or your breathing getting worse? }\end{array}$ & 2.14 & 5.60 & 64 & 21 & 10 & 3 & 1 & $<1$ & $<1$ \\
\hline \multicolumn{10}{|c|}{ In general, during the past week, how much of the time } \\
\hline CCQ 5. Did you chough? & 0.67 & 0.05 & 14 & 20 & 28 & 21 & 8 & 3 & 7 \\
\hline \multirow[t]{2}{*}{ CCQ 6. Did you produce phlegm? } & 0.78 & -0.31 & 26 & 21 & 22 & 12 & 8 & 5 & 7 \\
\hline & $\begin{array}{l}\text { Skewness } \\
\text { (s.d. }=0.16 \text { ) }\end{array}$ & $\begin{array}{l}\text { Kurtosis } \\
\text { (s.d. }=0.31)\end{array}$ & $\begin{array}{c}\text { Not } \\
\text { limited } \\
\text { at all }\end{array}$ & $\begin{array}{c}\text { Very } \\
\text { slightly } \\
\text { limited }\end{array}$ & $\begin{array}{l}\text { Slightly } \\
\text { limited }\end{array}$ & $\begin{array}{l}\text { Moderately } \\
\text { limited }\end{array}$ & $\begin{array}{l}\text { Very } \\
\text { limited }\end{array}$ & $\begin{array}{l}\text { Extremely } \\
\text { limited }\end{array}$ & $\begin{array}{c}\text { Totally } \\
\text { limited/or } \\
\text { unable } \\
\text { to do }\end{array}$ \\
\hline \multicolumn{10}{|c|}{ On average, during the past week, how limited were you because of your breathing problems } \\
\hline CCQ 7. Strenuous physical activities? & 0.43 & -0.54 & 14 & 21 & 23 & 22 & 10 & 7 & 4 \\
\hline CCQ 8. Moderate physical activities? & 0.97 & 0.62 & 30 & 28 & 21 & 13 & 5 & 3 & 2 \\
\hline CCQ 9. Daily activities at home? & 2.11 & 5.02 & 57 & 24 & 9 & 6 & $<1$ & 2 & 1 \\
\hline CCQ 10. Social activities? & 2.50 & 7.58 & 62 & 23 & 8 & 3 & 1 & 1 & 1 \\
\hline
\end{tabular}

'cough' was found to be $\mathrm{H} 0.76$. 'General impact' was covered by eight items with $a=0.91$, 'cough' was covered by two items with $a=0.84$.

Replication of findings in study 2

Neither the structure found in the first study (CFI 0.87, NFI 0.85 RMSEA 0.14, lower limit 0.12) nor the original model (CFI 0.80, NFI 0.79 , RMSEA 0.18, lower limit 0.16) revealed an adequate fit of the data. An inadequate model fit can be the result of severe violations of normality. Therefore, skewness, kurtosis and response distributions were reviewed again, and the results were consistent with those of study 1 (Table 4). Subsequently removing items 3, 4, 9 and 10 from the model because of floor effects and non-normal distributions led to an excellent model fit with two, more homogeneous dimensions measuring 'dyspnoea' $(a=0.86)$ and 'cough' ( $a=0.86)$ (Figure 2): CFI 0.98; NFI 0.97; RMSEA 0.08 and lower limit 0.04. Moreover, the remaining items cover the frequency and impact of the key symptoms that characterise an exacerbation (dyspnoea, cough and sputum production). ${ }^{25}$

\section{DISCUSSION}

Main findings

The aim of the present study was to examine the psychometric properties of the CCQ. Both exploratory (study 1) and confirmatory (study 2) factor analyses were conducted to discover its latent structure. EFA and Mokken scale analysis revealed a structure with two dimensions measuring the general impact of COPD, cough and phlegm production. The stability of this structure was, however, not confirmed in the second study, nor was the stability of the original structure with three dimensions. An inadequate fit can be caused by many different things, among which severe violations of normality as found in items $3,4,9$ and $10 .^{18}$

Interpretation of findings in relation to previously published work Nonetheless, the guidelines on developing instruments that measure patient-reported outcomes clearly state that statistical analyses should guide, not dictate, the process of scale development, ${ }^{26}$ the relevance of specific items and constructs to the patient and their clinical importance should also always be considered. ${ }^{26}$ The content of items 3, 4, 9 and 10 covered issues such as being concerned/depressed because of one's breathing problems and feeling limited in daily and social activities. However, in the Netherlands, primary care patients with COPD most likely suffer from a mild form of COPD (GOLD I and GOLD II) that does not necessarily lead to functional limitations in their daily and social activities or cause anxiety or depression because of their breathing problems. Therefore, one could choose not to include these items when using the CCQ in a primary care COPD population. Removing items 3, 4, 9 and 10 from the model resulted in an excellent fit with two homogenous dimensions, measuring both the frequency and impact of dyspnoea and the frequency of coughing and producing phlegm. Subsequently, the remaining six items may be a useful tool to screen for exacerbations. An exacerbation is characterised by 'worsening dyspnea, cough, sputum production and sputum purulence, as well as worsening airflow obstruction, ${ }^{27}$ which are symptoms covered by the remaining items. As can be seen in Figure 1, the 'cough' items were correlated with each other and the dyspnoea subscale. We chose not to include a 'cough' subdimension because there is debate on whether two items are sufficient to measure an overall underlying construct. ${ }^{28,29}$ However, when the CCQ is used to compare patients from primary care with those from, for example, secondary or tertiary care, the items on being concerned, depressed and/or limited in daily and social functioning could be relevant.

Implications for clinical practice and future research

Taken together, when using the CCQ in primary care patients with COPD one should be aware of the considerable differences between the originally described scale structure, ${ }^{3}$ and the structure that was discovered in the present study. On the basis of the present results, we recommend the use of an alternative, shortened version of the CCQ containing six items on dyspnoea and cough to screen for exacerbations. 


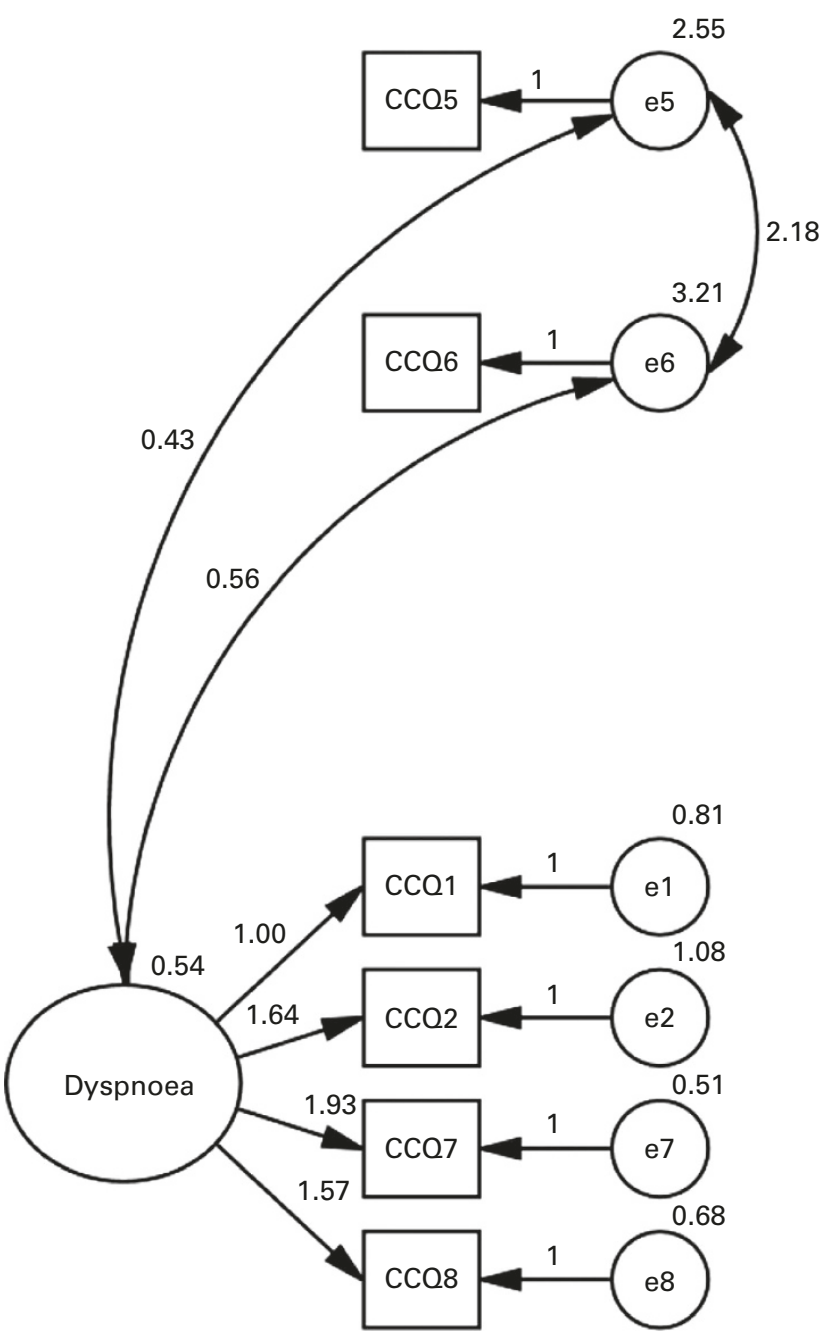

Figure 2. Best-fitting model from the confirmatory factor analysis in study 2.

To develop a questionnaire that measures the full range of clinical impairment related to COPD, the use of both qualitative and quantitative methods is essential. For this purpose, the relevant aspects of perceived functional impairment should be obtained from focus group interviews with patients and healthcare workers (including COPD experts, nurses and pulmonologists). Subsequent appropriate statistical methodology, i.e., factor analyses followed by reliability (internal consistency, test-retest) and concurrent and convergent validity analyses, should guide the process of item reduction and structure development. The guidelines even state that 'a questionnaire is not considered valid until the statistical properties have been tested'. ${ }^{26}$ The methodology that was used to develop the CCQ does not meet all of these criteria. For example, no statistical procedures or techniques were used to guide and validate the process of item selection and determining scale structure; instead this process was based on experts' opinions. As a consequence, the original scale structure was not confirmed by factor analysis and some items appeared not to be relevant.

Strengths and limitations

The key strengths of the present study design are the use of both confirmatory and exploratory factor analyses to determine the latent structure of the CCQ. Furthermore, both studies were conducted in relatively large samples of patients with COPD who were diagnosed according to the GOLD guidelines.

Limitations of the study include the relatively low response rate and the inclusion of primary care patients only, which may bias the results and limit generalisation to more severe patients; however, the CCQ was developed primarily for use in primary care as reflected in the patient population included by van der Molen et $a l^{3}$ In addition, there might be some overlap between the two samples that were combined. However, the second study sample was relatively small $(N=85)$ and their data were collected 2 years after the data collection of the first sample had finished.

\section{Conclusions}

This study revealed a clear two-component structure of the CCQ that, in a shortened version, could be an excellent instrument to screen for patient-reported exacerbations of COPD. Future research should further validate the stability and test-retest validity of the CCQ dimensions in primary care patients and in patients with advanced COPD. Our findings clearly support the potential usefulness of the CCQ to screen for exacerbations of COPD as a major patient-reported outcome measure.

\section{ACKNOWLEDGEMENTS}

We acknowledge PoZoB for providing us with data to conduct this study.

\section{CONTRIBUTIONS}

The study was designed by VJP, FP, JD and AMP. All authors have made substantial contributions to the acquisition, analyses and interpretation of the data; and were involved in drafting the manuscript and revising it critically for important intellectual content. All authors have given final approval for its submission.

\section{COMPETING INTERESTS}

The authors declare no conflict of interest.

\section{FUNDING}

No funding to declare.

\section{REFERENCES}

1 Global Initiative for Chronic Obstructive Lung Disease (GOLD) guideline: Global strategy for diagnosis, management and prevention of COPD 2011. http://www.goldcopd.org/uploads/users/files/GOLD_Report_2011_Feb21.pdf, accessed on November 2012.

2 World Health Organization 2011. World Health Report. Available from URL http:// www.who.int/gho/publications/world_health_statistics/en/index.htmlJanuary 2012.

3 van der Molen T, Willemse B, Schokkers S, ten Hacken NH, Postma DS, Juniper EF. Development, validity and responsiveness of the clinical COPD questionnaire. Health Qual Life Outcomes 2003; 1: 13.

4 Juniper EF, O'Byrne PM, Guyatt GH, Ferrie PJ, King DR. Development and validation of a questionnaire to measure asthma control. Eur Respir J 1999; 14: 902-907.

5 Streiner DL, Norman GR. Health Measurement Scales: A Practical Guide to their Development and Use, 4th edn. Oxford University Press, New York, NY, USA, 2008.

6 Ställberg B, Nokela M, Ehrs P, Hjemdal P, Jonsson EW. Validation of the clinical COPD questionnaire (CCQ) in primary care. Health Qual Life Outcomes 2009; 7: 26.

7 Kocks JWH, Tuinenga MG, Uil SM, van den Berg JW, Ståhl E, van der Molen T. Health status measurement in COPD: the minimal clinically important difference of the clinical COPD questionnaire. Respir Res 2006; 7: 62.

8 Kocks JWH, Kerstjens HAM, Snijders SL, de Vos B, Biermann JJ, van Hengel P et al. Health status in routine clinical practice: validity of the clinical COPD questionnaire at the individual patient level. Health Qual Life Outcomes 2010; 8: 135.

9 Reda AA, Kotz D, Kocks JWH, Wesseling G, van Schayck CP. Reliability and validity of the clinical COPD questionnaire and chronic respiratory questionnaire. Respir Med 2010; 104: 1675-1682. 
10 Jones PW. COPD: functional status, health status and primary care. Prim Care Respir J 2011; 20: 227-228.

11 Kocks JWH, Asijee GM, Tsiligianni IG, Kerstjens HA, van der Molen T. Functional status measurement in COPD: a review of available methods and their feasibility in primary care. Prim Care Respir J 2011; 20: 269-275.

12 Stucki A, Stucki G, Cieza A, Schuurmans MM, Kostanjsek N, Ruof J. Content comparison of health-related quality of life instruments for COPD. Respir Med 2007; 101: 1113-1122.

13 Stull DE, Kline Leidy N, Jones PW, Ståhl E. Measuring functional performance in patients with COPD: a discussion of patient-reported outcome measures. Curr Med Res Opin 2007; 23: 2655-2665.

14 Bausewein C, Farquhar M, Booth S, Gysels M, Higginson IJ. Measurement of breathlessness in advanced disease: a systematic review. Respir Med 2007; 101 399-410.

15 Koopmans B, Pouwer F, de Bie RA, Leusink GL, Denollet JK, Pop VJ. Associations between vascular co-morbidities and depression in insulin-naive diabetes patients: the DIAZOB primary care diabetes study. Diabetologia 2009; 52: 2056-2063.

16 Kuiper S, Smeele I, Vogelzang E et al. DBC COPD Ketenzorg heeft lucht 2007.

17 Pommer AM, Pouwer F, Denollet J, Pop VJ. Managing co-morbid depression and anxiety in primary care patients with asthma and chronic obstructive pulmonary disease: design of a randomized controlled trial. Trials 2012; 13: 6 .

18 Floyd FJ, Widaman KF. Factor analysis in the development and refinement of clinical assessment instruments. Psychol Assess 1995; 7: 286-299.

19 Gorsuch RL. Factor Analysis, 2nd edn. Erlbaum: Hillsdale, NJ, USA, 1983.

20 Sijtsma K, Molenaar IW. Introduction to Nonparametric Item Response Theory. Sage: Thousand Oaks, CA, USA, 2002.

21 Pallant J. SPSS Survival Manual, 2nd edn. Open University Press: New York, NY, USA, 2005.
$22 \mathrm{Hu} \mathrm{L}$, Bentler PM. Cutoff criteria for fit indexes in covariance structure analysis: conventional criteria versus new alternatives. Struct Equ Modeling 1999; 6: 1-55.

23 Browne MW, Cudeck R. Alternative ways of assessing model fit. In: Testing Structural Equation Models Bollen K, Long J (eds) Sage: Newbury Park, CA, USA, 1993.

24 Insley HEA, Brown SD (eds) Handbook of Applied Multivariate Statistics and Mathematical Modeling. Academic Press: CA, USA, 2000.

25 Miravitlles M. Cough and sputum production as risk factors for poor outcomes in patients with COPD. Respir Med 2011; 105: 1118-1128.

26 Crawford B, Monz B, Hohlfeld J, Roche N, Rubin B, Magnussen H et al. Development and validation of a cough and sputum assessment questionnaire. Respir Med 2008; 102: 1545-1555.

27 Aaron SD, Donaldson GC, Whitmore GA, Hurst JR, Ramsay T, Wedzicha JA. Time course and pattern of COPD exacerbation onset. Thorax 2012; 67: 238-243.

28 Kline RB. Principles and Practice of Structural Equation Modeling, 2nd edn. The Guilford Press: New York, 2005, Chapter 7.

29 Arroll B, Khin N, Kerse N. Screening for depression in primary care with two verbally asked questions: cross sectional study. BMJ 2003; 327: 1144.

(c) (1) This work is licensed under a Creative Commons Attributioncc. Non Commercial-ShareAlike 4.0 International License. The images or other third party material in this article are included in the article's Creative Commons license, unless indicated otherwise in the credit line; if the material is not included under the Creative Commons license, users will need to obtain permission from the license holder to reproduce the material. To view a copy of this license, visit http:// creativecommons.org/licenses/by-nc-sa/4.0/ 